\title{
Diagnóstico de competitividad del sector productor de arracacha. Caso municipio de Boyacá (Colombia) 2014*
}

\section{Diagnostic of competitiveness of the producer} sector of Arracacia xanthorrhiza Bancroft. Case municipality of Boyacá (Colombia) 2014

\section{Diagnóstico do setor produtor de mandioquinha. Município caso de Boyaca (Colômbia) de 2014}

Diana Lizeth Rojas Cruz** Patricia Carolina Barreto Bernal***

Fecha de recepción: 15 de agosto de 2015

Fecha de aceptación: 24 de mayo de 2016

* El presente artículo es producto de un proyecto que se encuentra adscrito al grupo de investigación de proyectos organizacionales para el desarrollo empresarial de la región "PODER".

** Estudiante de la Especialización en Finanzas de la Universidad Pedagógica y Tecnológica de Colombia. Correo electrónico: dianalizeth.rojas@uptc.edu.co

*** Doctora en Administración de la Universidad de EAFIT. Coordinadora Grupo de Investigación "PODER”. Docente de planta Escuela de Administración de Empresas Universidad Pedagógica y Tecnológica de Colombia.

Correo electrónico: patricia.barreto@uptc.edu.co 


\title{
Resumen
}

El presente artículo analiza las condiciones de competitividad del sector productor de arracacha en el municipio de Boyacá y su influencia en dicho territorio. Para ello, se emplean los modelos "cinco fuerzas" y "diamante de competitividad" desarrollados por el profesor Michael Porter. Los resultados obtenidos permitieron establecer un diagnóstico cualitativo sobre la situación actual y las perspectivas de la cadena, dilucidándose factores clave que deben intervenirse en pro de propuestas generadoras de valor y oportunidades encaminadas a la construcción de alternativas en el área agroindustrial, que faciliten el acceso a nuevos mercados y provean, tanto crecimiento sostenible para la región, como mejor calidad de vida para los agricultores.

Palabras clave: arracacha, cadena productiva, desarrollo regional, competitividad.

\section{Clasificación JEL: Q10, R11}

\begin{abstract}
This article analyzes the competitiveness of the production sector of Arracacia xanthorrhiza Bancroft in the municipality of Boyacá, and its influence on the territory. For this purpose, "Five Forces" and "Diamond of competitiveness" models, developed by Professor Michael Porter, are employed.

The results obtained allowed establishing a qualitative assessment of the current situation and prospects of the chain, clarifying key factors that should be improved for generating value propositions and opportunities aimed at building alternatives in agribusiness, which facilitate access to new markets and provide both sustainable growth for the region as a better quality of life for farmers.
\end{abstract}

Keywords: Arracacia xanthorrhiza Bancroft, supply chain, regional development, competitiveness. 


\section{Resumo}

Este artigo analisa a competitividade do setor produtor de mandioquinha no município de Boyacá, e sua influência sobre o território. Para este efeito, os modelos das "cinco forças" e "diamante de competitividade", desenvolvido pelo professor Michael Porter é empregado.

Os resultados obtidos permitiram estabelecer uma avaliação qualitativa da situação atual e as perspectivas da cadeia , sendo esclarecida fatores chave que devem ser interceptados para gerar propostas de valor e oportunidades destinadas a construção de alternativas a nível agro- industrial, para facilitar o acesso a novos mercados e proporcionar tanto um crescimento sustentável para a região como uma melhor qualidade de vida dos agricultores.

Palabras chave: Mandioquinha, cadeia de suprimentos, desenvolvimento regional, competitividade. 


\section{INTRODUCCIÓN}

El sector agrícola constituye una fuente primordial de empleo para la población colombiana, siendo prioritario en los procesos de desarrollo económico y social. Por tanto, el Gobierno nacional y los entes territoriales han dirigido sus esfuerzos a fortalecer aquellos cultivos que representen sostenibilidad en tres campos: social, que permita garantizar calidad de vida a los agricultores; ambiental, en donde la actividad agrícola debe preservar el medio ambiente; y económico, generando ingresos sobre la base de ventajas comparativas y competitivas de sus producciones.

Es precisamente en este último campo donde centra especial atención el presente estudio, pues al ser Colombia un país con vocación agrícola, se debe propender al fortalecimiento y promoción de productos competitivos, y sobre todo ancestrales, pues constituyen una alternativa de diferenciación frente a otros mercados.

Uno de los principales productos ancestrales es la arracacha (Arracacia xanthorrhiza Bancroft), planta de cultivo tradicional cuyo estudio ha sido un poco insipiente en el país por parte de investigadores y entidades encargadas de generar o ejecutar las políticas de desarrollo agrícola en Colombia. Sin embargo, sus usos agroindustriales y farmacéuticos descubiertos recientemente han motivado el interés en este tubérculo milenario presente en nuestra cultura y que ha desempeñado un importante papel en la economía de productores en la región andina (Biocomercio, 2013 b).

En esta línea, el departamento de Boyacá pasa de ser el cuarto productor de arracacha a nivel nacional en 2008, a ser el tercer productor en 2013, después de Tolima y Norte de Santander; indicador positivo que posiciona a la especie como promisoria en el campo de la agroindustria (Ministerio de Comercio, Industria y Turismo, 2013).

El cultivo se encuentra catalogado dentro de la cadena de raíces y tubérculos andinos, subsector que para el departamento de Boyacá reporta una producción anual de 439.358 toneladas de alimentos, beneficiando a 20.000 familias y proporcionando 100.000 empleos directos (Gobernación de Boyacá, 2010). No obstante, los agricultores se han visto afectados en dicho subsector por una tendencia nacional, caracterizada por producción para autoconsumo, abandono de zonas rurales y difícil acceso a los factores productivos; elementos que en su conjunto, no permiten a estos actores responder de manera efectiva a los requerimientos dados tanto por el mercado nacional como internacional.

A nivel regional se reconoce que el principal productor de arracacha es el municipio de Boyacá ${ }^{1}$, dado por las ventajas comparativas con que cuenta el territorio

\footnotetext{
1 Municipio ubicado en la cordillera Oriental de los Andes colombianos, perteneciente al departamento de Boyacá. Geográficamente se encuentra conformado por once veredas: Huerta Chica, Rique, Vanega Norte, Vanega Sur, Rupaguata, Pachaquira, Siraquita, Soconsaque Oriente, Soconsaque Occidente, Huerta Grande sector 1, Huerta Grande sector 2 y Centro.
} 
para su siembra, figuradas en variables de clima y suelo, aunadas a la vocación tradicional de los agricultores boyacenses. "Así, su producción anual promedio para 2012 alcanzó las 1.500 toneladas; frente a otros municipios como Tibaná, Ciénega y Ramiriquí, cuyos volúmenes en toneladas para el mismo año fueron de 1.187, 625 y 610, respectivamente" (Ministerio de Agricultura y Desarrollo Rural, 2013)

Ligada a la tradición adquirida de los ancestros, la arracacha representa una parte considerable en los ingresos de agricultores boyacenses, y de acuerdo con los datos presentados por Enrique Alvarado (2010) en su trabajo Cultivo de arracacha (arracacia xanthorrhiza Bancroft): en los municipios de Turmequé y Boyacá, el 40 \% de los campesinos emplea más de la mitad del área de siembra para el cultivo de la especie, dejando la proporción restante para producción de maíz, haba y leguminosas de tipo semestral. Por consiguiente, es común encontrar siembra en la denominada compañía o sociedad campesina, donde cada uno de los agentes interventores aporta elementos para la producción, como semillas, mano de obra, tierra, insumos y capital, apelando a la distribución de los ingresos según lo pactado.

El municipio en estudio, al ser un productor tradicional de arracacha y ver representados buena parte de sus ingresos en esta, requiere atención prioritaria en la materia, pues no es ajeno a la tendencia agrícola na- cional, en la que son menores los esfuerzos para potenciar la cadena productiva y los campos explorados que permitan la construcción de oportunidades para la misma. Aunado a ello, se resalta que investigadores y entidades que ejecutan políticas de desarrollo agrícola en la región no han fijado la atención necesaria en el cultivo, lo que ha propiciado el desaprovechamiento de todo su potencial, el cual se dirige a generar grandes expectativas socioeconómicas rentables, pudiendo ampliarse su área con un grado de tecnificación, que le permita proyectarse como un producto promisorio en seguridad alimentaria.

Es allí, precisamente, donde recae uno de los factores clave de análisis, ya que la desatención de la especie y la falta de información ${ }^{2}$ en la materia limitan el acceso a fuentes alternas para mejorar la calidad de vida de los agricultores del municipio, quienes por desconocimiento de las condiciones competitivas del cultivo, encuentran una barrera en la proyección de la especie hacia nuevos mercados y proyectos enmarcados en políticas agrícolas que sigan las tendencias actuales que demandan productos de mayor valor agregado.

Finalmente, y como se describió en epígrafes anteriores, el desamparo de la especie en estudio por parte de entidades gubernamentales, sumado a la escasez de información en cuanto a puntos críticos en la cadena productiva, no permiten el

Se encuentra que sólo Biocomercio y la Corporación PBA han desarrollado en Colombia estudios sectoriales sobre la competitividad de la arracacha y los tubérculos andinos. A nivel internacional, son estas mismas entidades las que han desarrollado análisis en el campo en países como Brasil, Perú y Ecuador. 
diseño y ejecución de políticas agrícolas que promuevan el desempeño óptimo en el sector productivo de la arracacha no solo a nivel regional sino también nacional. Por lo anterior, esta investigación servirá, a su vez, de apoyo a nivel micro a una de las grandes visiones del plan regional de competitividad del departamento de Boyacá 2008-2032, bajo el objetivo estratégico encaminado a "propiciar el desarrollo productivo de sectores agrícolas; fomentando la competitividad a largo plazo a través de productos funcionales, saludables y de alta calidad".

\section{FUNDAMENTACIÓN TEÓRICA}

El término competitividad ha sido estudiado desde diversas perspectivas en el ámbito académico, llegándose a la conclusión de que el concepto involucra una serie de componentes que divergen del alcance y del punto de análisis que se desee estudiar, según la región y sector a que se refiera.

Al entenderse la competitividad como la "capacidad de una industria o sector para producir bienes con patrones de calidad específicos, utilizando más eficientemente recursos que empresas o industrias semejantes en el resto del mundo durante un cierto período de tiempo" (Haguenauer, 1990), es preciso destacar que se ha convertido en el nuevo punto focal de los estudiosos en administración, pues si bien es cierto, y de acuerdo con las corrientes económicas clásicas, la ventaja comparativa constituye un elemento clave en el desarrollo de los países y en el mercado moderno.
Crear y desarrollar una ventaja competitiva demanda de las regiones un despliegue de recursos y habilidades, reconocidos como competencias distintivas, que terminan por moldear la eficacia en la ejecución de cada uno de los encadenamientos (Berumen, 2006, p. 149).

Es evidente que la competitividad tiene una relación estrecha con la generación de valor, en la medida en que esta última permite a las cadenas productivas diferenciarse y posicionarse dentro de su sector, reconociendo su capacidad de respuesta y flexibilidad. Las cadenas productivas, como unidad analítica, ocupan un lugar de gran importancia dentro del diseño de las políticas de promoción e intervención en programas de asociatividad y cooperación en las regiones (Isaza, 2008, p. 15).

Por otra parte, un sector competitivo se distingue en la medida en que, de forma consciente, realiza un esfuerzo constante, con el fin de crear las condiciones que le permitan elevar los niveles de preferencia hacia sus productos o servicios por parte de los integrantes de su mercado o elevar barreras que impidan que sus posiciones de mercado sean erosionadas por competidores (Cabrera, López \& Ramírez, 2011).

El sector requiere identificar su capacidad competitiva para sentar las bases de la generación de valor y beneficio obtenido. Esta identificación puede efectuarse a partir de estudios en materia de competitividad, cuyo objetivo general sea "fortalecer la capacidad de gestión, para comprender los alcances de acuerdos comerciales, 
tecnológicos y de desempeño y medir su impacto sobre el sector productivo, de manera que se pueden diseñar estrategias y programas a mediano y largo plazo concertados y dirigidos al mejoramiento de la competitividad" (López, 2010).

El territorio, por su parte, es un elemento que también juega un rol importante en el crecimiento regional, ya que "como espacio de desarrollo, permite la combinación del capital humano y los recursos naturales que fortalecen el tejido social posibilitando la transformación productiva y la competitividad" (Cardona, Castiblanco \& Díaz, 2013, p. 152).

Por consiguiente, la cadena productiva es un factor clave en la dinámica de la industria, que configura la perspectiva de desarrollo del territorio donde funciona (Gereffi, 2001, p. 9).

En efecto, son amplios los estándares desarrollados para la medición de la competitividad; sin embargo, pocos son aplicables a pequeñas economías, con diversas restricciones y un manejo ineficiente de los factores de producción.

Por ello, el presente estudio empleó los modelos denominados diamante de competitividady cincofuerzas, los cuales fueron desarrollados por el profesor Michael Porter, y tienen por finalidad determinar la sostenibilidad de un sector a largo plazo, y evaluar, principalmente, los factores que afectan la competitividad de una región y que inciden en la rentabilidad de este, pues la flexibilidad de sus enfoques admite tomar como unidad de análisis la cadena productiva y los vínculos de su eslabonamiento dentro del territorio.

El diamante de competitividad es un modelo en el que confluyen cuatro elementos base, que interactúan de manera dinámica y permiten establecer el éxito competitivo de la cadena productiva en una región, ya que "las diferencias en la dotación de factores reflejan el ritmo de crecimiento de las economías regionales" (Rodríguez, 2014, p. 243). En este sentido, el modelo aplica el análisis de variables que afectan a todo el sector, las cuales pueden apreciarse en la Figura 1.

De igual manera, es importante traer a colación el modelo conocido como "las cinco fuerzas de Porter", pues el atractivo de la industria es uno de los fundamentos determinantes en la rentabilidad del sector, en la medida en que "de la estructura de la industria depende quien recibe el valor" (Porter, 1999, p.8). De acuerdo con el modelo citado, la idoneidad de la industria se concentra en cinco fuerzas de la competencia (véase Figura 2). Así pues, la composición de la industria es indispensable para medir la rapidez con que la oferta se ajusta a la demanda, y la relación propia entre la utilización del capital con la rentabilidad.

La fuerza combinada de los cinco factores determina la capacidad de las compañías de un sector para ganar tasas de rendimiento o sobre la inversión, que superen el costo del capital (Porter, 1999); vislumbrándose entonces, características económicas y técnicas 
de la industria que son propias de ella, dependiendo en amplio grado de su estructura.

Finalmente, al compaginar los modelos descritos, se encuentra que la estructura que rija en el sector, establece de manera directa quién conserva el valor generado por la empresa y en qué proporción. Asimismo, teniendo en cuenta dicha estructura se determina la rapidez con que los competidores incrementan la oferta, al igual que la altura en las barreras contra el ingreso de participantes $\mathrm{y}$, de manera directa, la rentabilidad en el sistema.

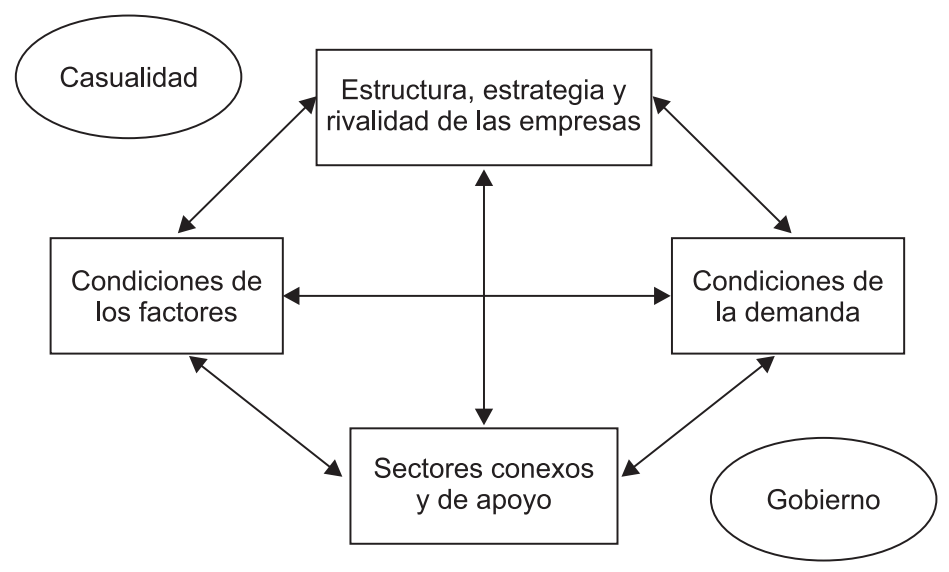

Figura 1. Diamante de competitividad

Fuente: Michael Porter (1991).

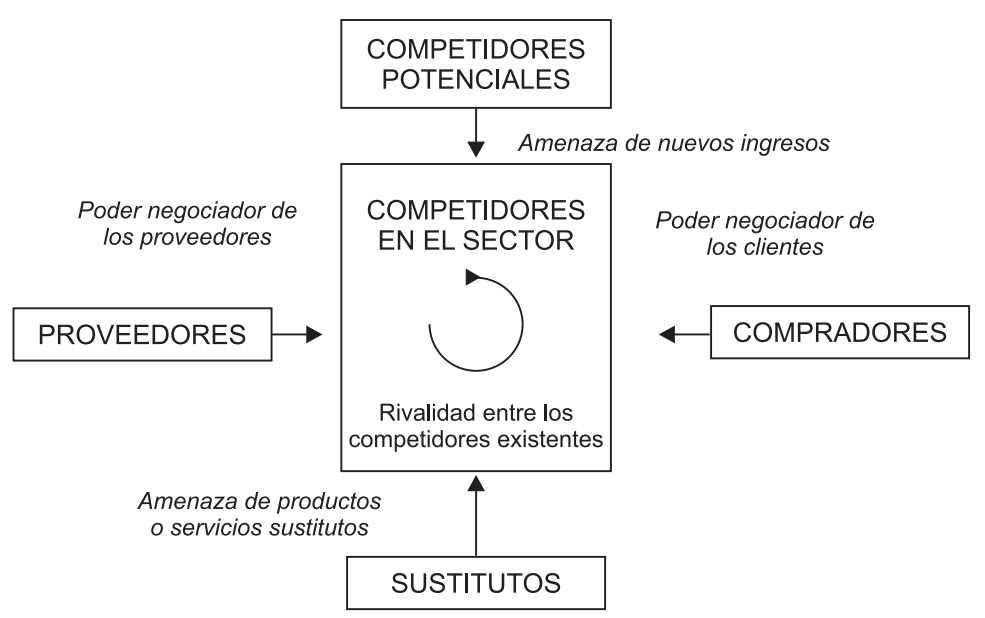

Figura 2. Cinco factores de la competencia que determinan la rentabilidad de una industria. "Cinco fuerzas de Porter".

Fuente: Michael Porter (1999). Estrategia competitiva: Técnicas para el análisis de los sectores industriales y la competencia. 


\section{Generalidades de la arracacha}

La arracacha, cuyo nombre científico es arracacia xanthorrhiza, es un producto agrícola que se cultiva en su mayoría en tierra de clima frio y su consumo es muy popular en la zona andina de América. “..., sus usos industriales han sido poco explorados encontrándose unos pocos como son la elaboración de sopas o compotas y rodajas deshidratadas para freír, a pesar de su amplio valor nutricional, dado en carbohidratos (24.9 g), proteínas $(1,1 \mathrm{~g})$ y un alto nivel de agua $(71.9$ g)" (Nonsoque \& Suárez, 1991, p. 5).

Profundizando en el entorno botánico de la especie, se encuentra que es "Una planta herbácea de producción anual, con periodo vegetativo de 8 a 12 meses, raíces carnosas y comestibles; el color de las raíces varía del blanco al purpura; produce de 4 a 10 raíces fusiformes de 5 a $15 \mathrm{~cm}$ de largo por 3-8 de diámetro. Hojas pinatisectas de morfología similar al apio (Alvarado, 2010, p.3).

En cuanto a su sistema de cultivo, la arracacha suele sembrarse sola o en asocio con otra especie como maíz o frijol, y en algunas zonas es intercalada con los cafetales. Su siembra suele iniciar en el primer trimestre de año, para aprovechar la abundancia de lluvia, donde los surcos tienen una distancia de un metro y de $0.50 \mathrm{~m}$ entre cada planta; así, para una densidad aproximada de 20.000 plantas es preciso el empleo de una hectárea de tierra, obteniendo resultados de 17 toneladas por dicha extensión (Alvarado, 2010, p.7)

Por otra parte, hay que señalar que la especie se puede agrupar en tres clases de acuerdo con el color de sus raíces: la raíz blanca denominada Salamineña blanca, la raíz amarilla o yema de huevo y la raíz morada, cuya popularidad es menor (Muñoz, Alvarado \& Almanza, 2014). En efecto, la raíz es la parte vital del cultivo, puesto que constituye la porción comercial y comestible de este, donde se destaca que la variedad de la especie adecuada es aquella con mayor peso de la raíz.

Por último, se anota que esta especie no requiere minuciosos o estrictos controles de malezas y plagas; sin embargo, la desyerba y el aporcamiento en el cultivo son importantes durante los primeros cinco meses.

De manera que, el seguimiento en la cadena de la especie permitirá, por una parte, ofrecer al consumidor un producto agrícola de valor, bajo altos estándares de seguridad alimentaria, y, por otra, aumentar la productividad de la misma, lo que repercute directamente en el desarrollo sostenible de la zona agrícola productora.

\section{METODOLOGÍA}

Este es un estudio de tipo deductivo, en el que se parte de una premisa general para obtener las conclusiones de un caso particular. Se aplican los modelos 
diamante de competitividad y cinco fuerzas del profesor Michael Porter, al caso particular del sector arracachero y su entorno productivo en el municipio de Boyacá.

Dadas las condiciones anteriores, la investigación se desarrolló bajo un enfoque cualitativo, fundado en que todo sistema tiene un modo único para entender determinada situación o evento que en dicho sistema se sucede, que permite reconocer el fenómeno tal cual es en su especificidad, en el que convergen la realidad del investigador, la de los participantes y el producto en la interacción de los actores involucrados.

La información se recopiló empleando como instrumento la observación no estructurada y la entrevista abierta a los actores representativos de la cadena productiva de la arracacha (agricultores, comercializadores, asociaciones de productores, Secretaría de Agricultura y Alcaldía del municipio de Boyacá) como fuente primaria. De igual manera, se destaca el análisis documental como instrumento de recolección en fuentes secundarias.

Se tuvieron en cuenta los datos estadísticos suministrados por la Esapgro del municipio de Boyacá, en donde para 2014 se reconocían 60 productores activos de arracacha. De modo tal, que la población total objeto de estudio fue de 60 agricultores, a los cuales se aplicaron los instrumentos de recolección de datos agendándose citas previas con los actores en sus fincas y parcelas de trabajo. Por su parte, se tomaron 14 distribuidoras agrícolas, 12 de la ciudad de Tunja y 2 del municipio de Boyacá, y los 15 mayoristas principales que comercializan el producto en la plaza de mercado de Tunja.

\section{LA DINÁMICA ECONÓMICA CAMPESINA ALREDEDOR DE LA ARRACACHA}

Es frecuente encontrar en la literatura académica de economía y administración desarrollos sobre la competitividad en sectores productivos de tipo industrial. Sin embargo, algunos referentes en México han comenzado a trabajar el tema de la empresarialidad rural revisando los tejidos productivos históricos de regiones de agricultura intensiva en un producto específico (Cerutti \& Almaraz, 2013), los cuales configuran una red empresarial poco estudiada a nivel de regiones minifundistas como Boyacá, pues por lo general, los estudios en Colombia se concentran en monocultivos como los de la caña de azúcar en el Valle, el arroz, la palma, el banano o el algodón en otras regiones del país, dejando un campo importante de análisis ubicado en la competitividad de las economías regionales que tienen una base predominantemente agrícola desde una perspectiva competitiva.

En diferentes investigaciones desarrolladas en el norte de México se ha indagado cómo a lo largo de la historia, los cultivadores de tomate, hortalizas, algodón, al instrumentar el concepto de sistema 
productivo local, "se analiza desde el surgimiento de agrociudades a partir de un entorno fundamentalmente agrícola, hasta el papel de las vías de comunicación y la infraestructura hidráulica en el desarrollo de su agricultura, categorías de análisis que han sido heredadas de la reciente historia económica del sur europeo" (Carrillo \& Cerutti, 2006, p. 12).

Tales referentes permiten evidenciar la oportunidad de que a partir del análisis de los sistemas de encadenamiento productivo en sectores rurales especializados en cultivos específicos, puedan ser proyectados para la configuración de dinámicas de competitividad más fuertes, tomando como base del mejoramiento de las condiciones de infraestructura y empresarialidad que aporten al desarrollo local y complementen las capacidades endógenas y conocimientos autóctonos, estos dos elementos diferenciadores en el mercado, pero insuficientes para competir en un mercado global. A continuación se presenta el resultado de la investigación que pretende dar un primer acercamiento a la reflexión sobre la productividad y competitividad campesina en el caso de la arracacha en el municipio de Boyacá.

\section{Cadena productiva de la arracacha}

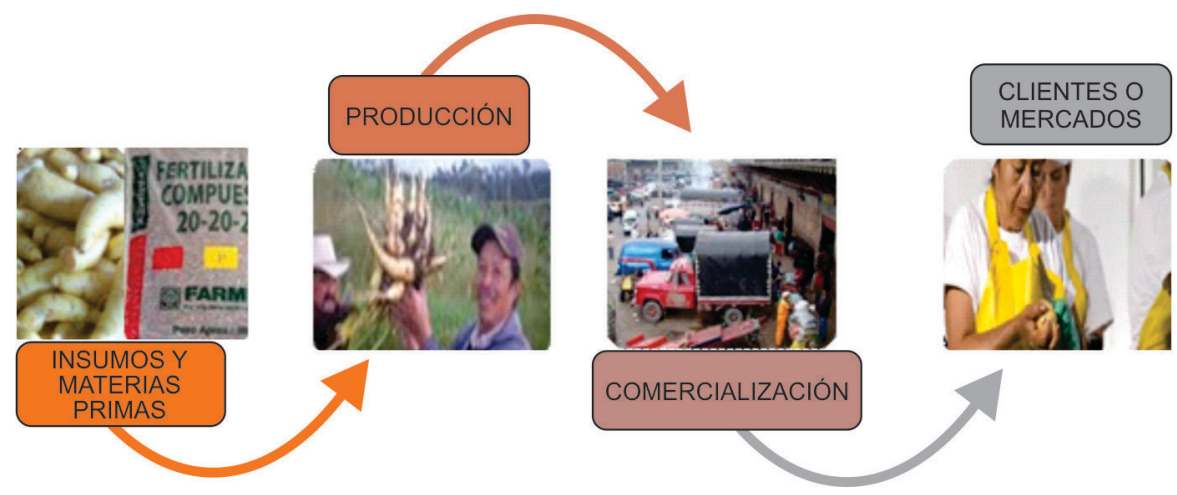

Figura 3. Cadena productiva de la arracacha en el municipio de Boyacá.

Fuente: elaboración de autores con base en Biocomercio (2013 b). Facilitación de financiamiento para negocios basados en la biodiversidad y apoyo a actividades de desarrollo de mercados en la región andina.

La cadena productiva de la arracacha se encuentra constituida por cuatro eslabones fundamentales, como lo indica la Figura 3. A continuación se describen las características principales para cada uno de ellos, considerando las particularidades que atañen al cultivo en el municipio de Boyacá. 


\section{Eslabón insumos y materias primas}

Está compuesto por aquellas compañías o empresas dedicadas a la comercialización de materiales básicos empleados en la producción de arracacha. En lo que se refiere a materias primas, se encuentra el colino, que es el material vegetativo de propagación asexual, el cual es cortado de la planta cosechada y puesto a desinfección, para luego emplearse como semilla.

Los colinos se obtienen ya sea de cosechas anteriores o por compra; para este último caso, el agricultor acude a los almacenes agrícolas presentes en el municipio de Boyacá, o la adquiere entre los vecinos.

Por su parte, los insumos empleados son fertilizantes, plaguicidas y abonos, adquiridos en los almacenes agrícolas de la ciudad de Tunja. La relación comercial entre el agricultor y su proveedor de insumos está dada por venta directa o mostrador, en donde el productor acude al distribuidor para realizar la transacción y obtiene facilidades de pago como créditos o descuentos.

Tabla 1. Costos de producción por hectárea

\begin{tabular}{|l|c|}
\hline ACTIVIDAD & VALOR \\
\hline Labores del cultivo & 998.029 \\
Insumos & 1.220 .728 \\
Otros costos & 455.490 \\
Costo x hectárea & 2.674 .247 \\
Rendimiento (Ton/Hec) & 16.6 \\
Densidad por hectárea & 151.500 \\
Utilidad aproximada & 2.990 .153 \\
\hline
\end{tabular}

Fuente: elaboración de las autoras, con base información suministrada por productores de arracacha municipio de Boyacá, 2014.

\section{Eslabón de producción}

La arracacha es una planta andina, de la familia de las apiaceas, reconocida con el nombre científico de arracacia xanthorrhiza Bancroft, que se desarrolla mejor desde los 1800 hasta los 2500 $\mathrm{msnm}$. Se cultiva principalmente por su raíz conservante que es de sabor agradable y de fácil digestibilidad, ya que posee un almidón muy fino, con alto contenido de calcio y vitamina A (Alvarado, 2010).
Sus variedades y materiales genéticos dependen de la zona geográfica donde se le cultiven, y al compararse con productos sustitutos como la papa criolla y la yuca, se tiene que su contenido en vitaminas $\mathrm{B}$ es mayor (véase Tabla 2). Cabe resaltar, que las vitaminas del complejo B proveen al cuerpo energía a partir de los alimentos y mantienen el sistema nervioso en buenas condiciones al igual que el sistema cardiovascular. 
Tabla 2. Contenido de vitaminas B1, B2 y B3 en la papa, arracacha y yuca

\begin{tabular}{|l|c|c|c|}
\hline VITAMINA mg & ARRACACHA & PAPA & YUCA \\
\hline Niacina B3 & 2.84 & 1.85 & 0.66 \\
Riboflavina B2 & 0.08 & 0.06 & 0.04 \\
Tiamina B1 & 0.09 & 0.07 & 0.03 \\
\hline
\end{tabular}

Fuente: elaboración de las autoras con base en Alvarado (2010). Cultivo de arracacha (arracacia xanthorrhiza Bancroft): en los municipios de Turmequé y Boyacá.

La arracacha constituye un cultivo de gran importancia en los ingresos de los campesinos del municipio de Boyacá, quienes cuentan con vocación y tradición en el cultivo de esta especie; aunado a las ventajas comparativas del territorio en lo que respecta a clima y fertilidad de los suelos. Así, se reconocen la variedad yema de huevo y palirrucia como las más comercializadas.

Se observa que las tierras empleadas para la producción de arracacha pertenecen, en su mayoría, a los labriegos que las cultivan, los cuales poseen vivienda en esos mismos terrenos. Este hecho indica un patrón de asentamiento de granja dispersa, característico en el departamento de Boyacá, patrón que se puede ratificar en los estudios realizados por el profesor Orlando Fals Borda (2010, p. 16), quien describe que las granjas dispersas son "construcciones más próximas unas a otras debido al pequeño tamaño de las propiedades donde están situadas; y la forma irregular de los lotes".

Las viviendas son elaboradas en material de adobe o bahareque con piso de tierra, en pequeñas fincas que abarcan en promedio las 2 y 4 hectáreas, donde a su vez ejercen la crianza de animales. 


\section{Proceso productivo}

\begin{tabular}{|c|c|}
\hline PROCESO & DESCRIPCIÓN \\
\hline $\begin{array}{l}\text { Materias primas } \\
\text { e insumos }\end{array}$ & $\begin{array}{l}\text { Se reciben las materias primas e insumos implicados en el proceso productivo, tales } \\
\text { como: colinos, fertilizantes, abono, cal, entre otros. }\end{array}$ \\
\hline $\begin{array}{l}\text { Manejo de } \\
\text { colinos }\end{array}$ & $\begin{array}{l}\text { Para la correcta selección de un colino que permita alta productividad en el cultivo, } \\
\text { es preciso que la edad de la planta madre oscile entre los } 7 \text { y } 9 \text { meses, con un ápice } \\
\text { en el colino de } 2 \text { a } 5 \mathrm{~cm} \text {. Luego se procede al lavado del colino y posteriormente } \\
\text { se realiza la desinfección con un rociado de cal apagada, para finalmente pasar a } \\
\text { secado bajo la sombra durante } 2 \text { o } 3 \text { días. } \\
\text { Por último, se efectúa un corte transversal al colino, eliminando hojas y partes } \\
\text { sobrantes, para facilitar el enraizamiento de la planta. }\end{array}$ \\
\hline Alistamiento & $\begin{array}{l}\text { Comienza con una remoción de tierra de } 2 \text { a } 4 \text { veces con arado, donde el suelo } \\
\text { debe ser profundo y contar con un pH entre } 5 \text { y } 6 \text {. De esta manera, debe aplicarse } \\
\text { un primer abonado y aporque. Las camas o surcos deberán tener una distancia entre } \\
\text { ellos de } 70 \text { a } 80 \mathrm{~cm} \text { y entre plantas de } 30 \text { a } 40 \mathrm{~cm} \text {. El ancho del surco depende del } \\
\text { tipo de colino seleccionado. }\end{array}$ \\
\hline Siembra & $\begin{array}{l}\text { Una vez se tienen listos los surcos, se realiza la siembra con el corte del colino hacia } \\
\text { arriba, a fin de aumentar la productividad del cultivo. Cada planta debe ser sembrada } \\
\text { de manera individual y en posición vertical. Así, por cada hectárea de tierra se tienen } \\
\text { en promedio } 40.000 \text { plántulas cultivadas. }\end{array}$ \\
\hline $\begin{array}{l}\text { Labores } \\
\text { agrícolas }\end{array}$ & $\begin{array}{l}\text { Durante el ciclo de producción de arracacha es indispensable el riego frecuente al } \\
\text { cultivo, lo que facilitará en las primeras etapas el enraizamiento del colino. Los pri- } \\
\text { meros indicios se presentan a los } 45 \text { días posteriores a la siembra, cuando el colino } \\
\text { empieza a brotar las raíces de reserva. } \\
\text { El control de maleza se efectúa dentro y fuera del cultivo. A los dos meses de siembra } \\
\text { se hace el primer control, retirando la maleza que crezca junto a la planta. } \\
\text { Los abonos (de tipo } 20-20 \text { o } 10-30-10 \text { ) son aplicados entre los } 6 \text { y } 7 \text { meses, luego } \\
\text { de la siembra, procurando el suministro en las partes más estériles. A la par, es } \\
\text { necesaria la revisión continua de las tierras, pues pueden hacerse presentes plagas } \\
\text { y enfermedades, entre las más comunes pulguilla negra, nematodos, cercospora, } \\
\text { alternaría y pudrición radicular; para ello, se efectúan } 3 \text { aplicaciones de fungicidas } \\
\text { e insecticidas, cada } 1.5 \text { o } 2 \text { meses, durante un lapso de } 7 \text { meses. }\end{array}$ \\
\hline Cosecha & $\begin{array}{l}\text { El primer indicio para realizar la cosecha de arracacha, se encuentra en el color de las } \\
\text { hojas de la planta, pues estas empiezan a tomar una tonalidad amarilla y el diámetro } \\
\text { de la raíz oscila entre los } 3 \text { a } 4 \mathrm{~cm} \text {; lo cual, ocurre a partir de los } 12 \text { meses, con una } \\
\text { recolección escalonada hasta los } 18 \text { meses, cuidando que la planta no se pudra. Cabe } \\
\text { resaltar, que cuando la recolección comienza superados los } 12 \text { meses, el volumen de } \\
\text { la producción por planta sembrada es mayor. } \\
\text { Se hace necesario el empleo de herramientas como azadón y palas para desprender } \\
\text { del suelo de manera total la planta de arracacha, sin que se maltrate. }\end{array}$ \\
\hline Empaque & $\begin{array}{l}\text { Una vez separada la planta del suelo, se procede a retirar de ella los colinos que } \\
\text { servirán para el siguiente cultivo; el tronco es empleado para alimento de ganado; } \\
\text { las raíces son la parte comestible producto final del cultivo. } \\
\text { Dichas raíces son clasificadas en primera o segunda categoría, dependiendo de su } \\
\text { tamaño, y dispuestas en empaques de fique con capacidad de } 5 \text { arrobas cada uno. } \\
\text { Posteriormente, los bultos son entregados al acopiador o directamente al mayorista } \\
\text { para su comercialización. }\end{array}$ \\
\hline
\end{tabular}

Fuente: elaboración de las autoras con base en Gonzales y Guerra (2010). Evaluación de la producción y residuos de cosecha en dos variedades comerciales de arracacha en Boyacá. 


\section{Eslabón de comercialización}

La venta de arracacha se realiza los días miércoles en el municipio de Boyacá. El agricultor debe llevar su producción debidamente empacada en costales de fique (con un peso de 5 arrobas cada uno), hasta la carretera más cercana, generalmente empleando animales de carga desde su finca. Una vez se encuentre a orillas del camino, procede a descargar los bultos y apilarlos, a fin de que el mayorista revise el producto y fije su valor, teniendo en cuenta características de tamaño, color, calidad y precio establecido por oferta y demanda.

De esta manera, el mayorista paga de contado el valor pactado de compra, y procede a cargar el vehículo (sea propio o arrendado) para el transporte del producto, el cual se hace en compañía de otros cultivos, como la papa, el maíz y el haba.

Tabla 3. Precio promedio mensual por kilogramo de arracacha en fresco, 2014

\begin{tabular}{|c|c|c|c|c|c|c|c|c|}
\hline & Ene. & Feb. & Mar. & Abr. & May. & Jun. & Jul. & Ago. \\
\hline N. & 832 & 731 & 672 & 687 & 630 & 610 & 615 & 638 \\
T. & 640 & 615 & 570 & 635 & 540 & 580 & 500 & 660 \\
B. & 866 & 734 & 602 & 619 & 567 & 585 & 541 & 847 \\
\hline
\end{tabular}

T: Tunja, B: Bogotá, N: Nacional.

Fuente: elaboración de las autoras, con base en SIPSA (2014)

En la Tabla 3 se puede apreciar, que en lo corrido del año 2014, el precio por kilo de la arracacha en fresco presenta una tendencia a la baja, dado el mayor volumen de oferta del producto en los mercados mencionados. Por tanto, la disminución de su precio para este periodo, no favorece a los agricultores, como lo manifiestan en las entrevistas realizadas: "los precios de la arracacha en este momento no son favorables, hay temporadas que sí; lo que pasó en este momento fue que los paperos de los páramos se dedicaron a sembrar arracacha, porque la papa estaba tan barata hace un año, y ahorita tienen hectáreas de arracacha para sacar" (entrevista a Pacacira, 2014).

Se pueden destacar tres canales básicos de comercialización, predominantes en el municipio de Boyacá para el cultivo de arracacha (ver Figura 4). 


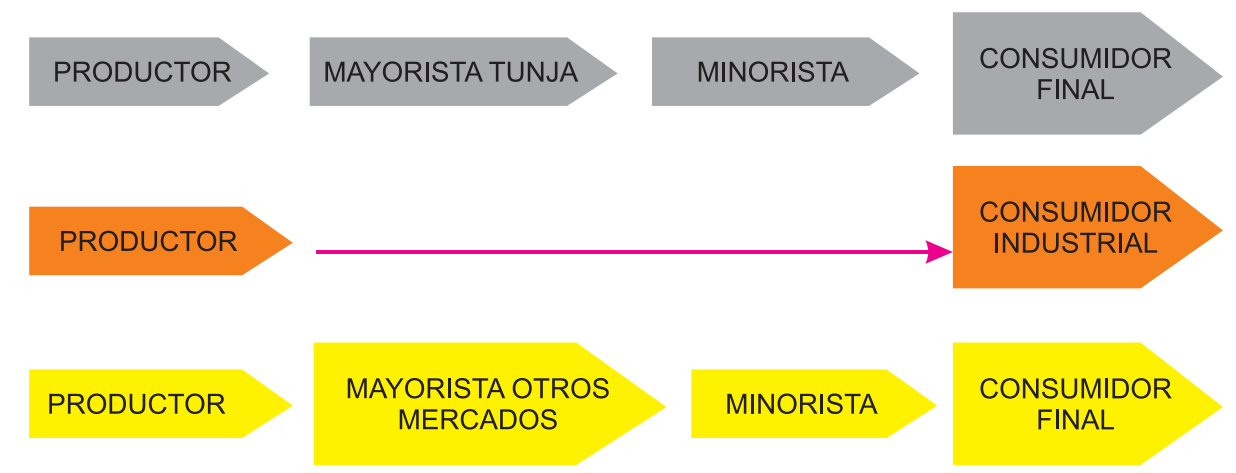

Figura 4. Canales de comercialización de la arracacha, municipio de Boyacá (Boyacá).

Fuente: elaboración de las autoras, con base en Nonsoque, y Suárez (1995). Estudio de la oferta de arracacha municipio de Boyacá.

Mayorista: se tiene como principal la plaza de mercado de Tunja, donde se negocia un volumen de 20 a 30 bultos por cada compra y hay un promedio mensual de venta de 100 bultos. De igual forma, existen otros mayoristas en mercados secundarios como en Bogotá, Aguazul y Santander.

Minorista: hace referencia a los supermercados y placitas campesinas, que distribuyen la arracacha en fresco, vendiéndola por libra o kilo.

Consumidor: es el actor final del canal de comercialización, que corresponde a: restaurantes, que la emplean en su menú para la preparación de sopas; consumidor doméstico y consumidor industrial, que la utiliza en la elaboración de tortas, pan y chips.

\section{Eslabón clientes o mercados}

Este eslabón se caracteriza por tener dos clases de consumidor. En primera instancia, se encuentra el consumidor doméstico, quien adquiere el producto a través de minoristas, para su empleo en preparaciones alimenticias para el hogar. De manera general, se compra el producto en fresco por libras a un precio que oscila entre los 600 a 700 pesos, dependiendo del valor transando en el mercado para el día.

El consumidor industrial es quien adquiere el producto en fresco principalmente en arrobas. En este caso, en el municipio de Boyacá existe Asipaboy, que cultiva y procesa la arracacha para venderla en forma de tortas, pan y chips, este último bajo la marca D'labranza. Asimismo, en el municipio, el señor Jairo Daza transforma la arracacha en torta y pan, y la comercializa en los mercados locales.

Al ser la arracacha un producto comercializado en fresco por tradición, sus consumidores tienen ciertas preferencias 
como lo son el color de la raíz que debe ser amarilla, el tamaño mediano y su presentación; para ello, se establece el producto como de primera o segunda categoría según el tamaño de la raíz.

Para la selección, el comprador observa cuidadosamente la raíz de la arracacha, de manera tal que no se encuentre descompuesta, puesto que la arracacha tiene una vida corta. Si es adquirida por libras, la revisión se efectúa raíz por raíz, pero si la compra se realiza por bultos, el cliente los destapa y observa las raíces que se encuentran en la base del empaque.

Así pues, en el sector productor de arracacha se tiene identificado cada uno de los eslabones que en el confluyen, cuya interacción permite establecer los requerimientos de sus actores. De esta manera, la producción tiene un destino final a partir de la transferencia que se hace del tubérculo en fresco desde el agricultor hasta el consumidor final, empleando sus canales de distribución.

En lo que respecta al eslabón de insumos y materias primas, cuenta con empresas establecidas que tienen presencia en otros puntos del país, conformadas por personal de formación técnica y profesional que conceden el adecuado asesoramiento y asistencia técnica. Aunado a ello, las facilidades de pago permiten el acceso oportuno del agricultor a los insumos agrícolas.

Por otra parte, en el eslabón de clientes se distingue a un consumidor entendido en el producto y con amplia experiencia en la compra del tubérculo, lo que pone en el agricultor el reto de implementar alternativas de producción innovadoras $y$ que sean acordes a los nuevos requerimientos de los mercados por alimentos orgánicos y saludables.

\section{Diamante de Porter}

Es una herramienta que permite medir la manera en que la nación crea fuerzas y las transmite a sus sectores; por consiguiente, a continuación se describirán los determinantes que conforman dicho diamante, para el caso de este estudio:

\section{Condiciones de los factores}

La dotación de factores con que cuente un territorio, marca un punto focal en la competitividad de los sectores económicos. En este sentido, dichos factores "no son cosa que pueda heredarse sino que se crean dentro de una nación, mediante procesos que difieren considerablemente de unas a otras naciones y entre los sectores de estas" (Porter, 1991, p.114).

\section{Recursos físicos}

El municipio de Boyacá brinda las condiciones físicas que facilitan la producción de arracacha, traducidas en un clima óptimo templado de $15^{\circ} \mathrm{C}$ y 2456 msnm; aunado a ello, al constituir dicho cultivo el $19 \%$ del total de las tierras aprovechadas para siembra que 
en el año 2012 fue de 2.332 hectáreas $^{3}$, se destaca la fertilidad y adecuación de los suelos nata para esta actividad agrícola. Asimismo, la cobertura en cuanto al 99 $\%$ en servicio de agua potable con red primaria de acueducto y alcantarillado, garantiza a los agricultores el suministro de este líquido vital, contándose con un tanque de distribución cuya capacidad es de 40.000 litros y un proyecto que se adelanta para la construcción de planta de tratamiento de aguas.

La ventaja geográfica de ubicación con que se cuenta en el municipio, permite a los agricultores de arracacha mantener un flujo comercial dinámico con sus mercados, ya que Boyacá limita con tres de sus cuatro mercados más importantes: Tunja, Ramiriquí y Jenesano; lo cual, facilita el manejo y transporte del producto en fresco, sobre todo al considerar su carácter perecedero, y los procesos de doble vía.

\section{Recursos humanos}

Actualmente, el municipio de Boyacá cuenta con una población de 4.522 habitantes, de los cuales el $8,8 \%$ reside en la cabecera municipal y el $91,2 \%$ restante vive en el área rural. (Dane, 2014). Los datos de la Alcaldía muestran que la estructura de la población se encuentra compuesta en un $49.1 \%$ por mujeres, las cuales se dedican a labores domésticas, cuidado de niños, y en menor proporción a la elaboración de alpargatas en fique. El $50.9 \%$ restante corresponde a hombres, quienes están encargados de todas las actividades agrícolas y pecuarias del campo (Concejo Municipal de Boyacá, 2012).

La población tiene acceso a la educación a partir de los cinco años (en un 48.6\% de los casos), a través de dos institucionescolegios -uno ubicado en el centro del municipio, y el otro en la vereda Huerta Grande- y de 11 escuelas -localizadas una por vereda-. Empero, "el 45,5\% de los habitantes ha alcanzado el nivel básico primario, el 25,1\% secundaria, el $5,9 \%$ ha alcanzado el nivel profesional y el 1,2 \% ha realizado estudios de especialización, maestría o doctorado" (Concejo Municipal de Boyacá, 2012).

La concentración del 91.2\% de la población en la zona rural, permite tener una amplia oferta de personal para las labores agrícolas, las cuales demandan a lo largo del ciclo productivo un promedio de 20 trabajadores por cada hectárea de cultivo.

Los jornaleros que son contratados, tienen la experiencia y los conocimientos necesarios en dicho campo, respaldados por una labor que aprenden y realizan desde pequeños y por la tradición oral de sus ancestros. Además, en la información

$3 \quad$ El remanente, el $17 \%$ con la papa y el $14 \%$ al cultivo de arveja. Por consiguiente, el $50 \%$ restante del área sembrada se distribuyó en 18 productos, como cebolla de bulbo, cilantro, ciruela, durazno, curuba, frijol, garbanzo, gulupa, haba, tomate de árbol, zanahoria, maíz, entre otros; Ministerio de Agricultura y Desarrollo Rural (2013). 
recolectada a dichos productores a través de entrevista directa, el $62 \%$ manifestó participar activamente en capacitaciones y proyectos dirigidos por la corporación PBA, por lo que han recibido formación técnica en materia de desinfección y corte de colinos, prácticas de siembra, reproducción in vitro, educación nutricional, agricultura orgánica y transformación de arracacha.

Por tanto, se destaca que el agricultor suele acudir a capacitaciones y participar en proyectos para el mejoramiento de su actividad agrícola, lo que permite el fortalecimiento del factor recursos humanos dentro del diamante de competitividad. Además, del $62 \%$ mencionado, el $30 \%$ tiene formación profesional en ingeniería agronómica, y el $15 \%$, diplomado en agricultura orgánica.

En lo que concierne a la jornada laboral y su coste, el agricultor trabaja en su propia parcela o alquila su trabajo a cambio de un jornal; prácticas que realiza durante todo el año. En el primer caso, se tienen unidades de producción familiar, en las que cada uno de los miembros del hogar realiza un aporte, ya sea de trabajo, capital o combinados. La retribución obtenida se divide entre los participantes, así como una parte determinada del cultivo (Fals, 2010, p. 110).

En el caso de los trabajadores que laboran por jornal, estos reciben un pago que varía de los $\$ 20.000$ a $\$ 25.000$, en donde el campesino labora 8 horas al día en un horario de 7 am a 5 pm y tiene derecho a recibir por parte del dueño de las tierras una comida, que generalmente es el almuerzo ${ }^{4}$.

De igual manera, los agricultores expresan que los pactos de trabajo son efectuados a través de contratos verbales, en los que se establecen el tiempo y lugar para desarrollar las respectivas labores en el cultivo. Por consiguiente, el trabajador se responsabiliza por terminar en el tiempo indicado las actividades encomendadas, así como por proveer las herramientas, tales como palas, picas, azadón, vitales para su trabajo.

El jornalero que trabaja en producción de arracacha en el municipio de Boyacá, normalmente es oriundo de esta zona, de la cual hereda todos los conocimientos que demandan las labores de este cultivo (dentro de las que se encuentran, corte de colino, siembra, deshierba, cosecha). Por tanto, cuando los agricultores contratan un jornal, tienen la certeza de que el trabajador cumple con la preparación necesaria para realizar las actividades que se requieran.

\section{Infraestructura}

Principalmente, se emplea el transporte terrestre para los productos agrícolas y pecuarios, teniéndose como vía primordial

\footnotetext{
Estos datos fueron suministrados por los agricultores de arracacha, encuestados en el municipio de Boyacá, 2014.
} 
aquella que atraviesa las veredas de Huerta Chica, Rique, Pachaquirá, Soconsaque y Huerta Grande. Dicha vía no se encuentra pavimentada, y por esta, a su vez, transitan animales de carga y personas. En esta medida, los transportadores de arracacha en fresco utilizan vehículos de carga, que no solo facilitan el acceso a las veredas, sino que también permiten transportar de manera conjunta otros productos como papa y maíz.

El casco urbano del municipio "Está conformado por una estructura vial discontinua debido a las características del terreno y a la misma conformación del manzaneo existente. Este no presenta ninguna reglamentación vial, debido a antigüedad del territorio. Exigiendo una oficina que funcione como ente regulador en el desarrollo de todo tipo de obras de infraestructura" (Concejo Municipal de Boyacá, 2012).

En cuanto a las vías comerciales, se encuentra que el municipio de Boyacá conecta con sus mercados principales de arracacha por la carretera principal, que está en un estado adecuado sin deslizamientos, ni hundimientos y facilita el transporte del producto. Así, en esta vía se llega por el occidente a Ramiriquí (15 minutos) y por el norte a Tunja (40 minutos), de donde se distribuye la arracacha hacia Bogotá y Santander.

Finalmente, vale destacar que el municipio de Boyacá se ve muy marcado por la vocación agrícola en el cultivo de la arracacha, pues los conocimientos en las labores culturales de este producto se heredan de padres a hijos, constituyendo una fuente vital de sus ingresos y de su gastronomía autóctona.

\section{Recursos de conocimiento}

En materia de unidades municipales que apoyan al sector productor de arracacha, existe la Entidad Prestadora de Servicios Agropecuarios (Epsagro), vinculada al Ministerio de Agricultura y Desarrollo Rural (2013), que reemplaza a la denominada Umata. Esta entidad se dedica a solventar servicios de asistencia técnica agropecuaria a todos los productores del municipio, bajo la dirección del ingeniero agrónomo Milton Pulido.

Por otra parte, hay que señalar el trabajo realizado por la Corporación para el Desarrollo Participativo y Sostenible de los Pequeños Agricultores (PBA), una organización sin ánimo de lucro, que trabaja con recursos de cooperación internacional y contrapartidas nacionales, en procesos de innovación participativa con pequeños agricultores en las áreas tecnológica, organizativa y empresarial, que contribuyan a mejorar la producción, los ingresos, los conocimientos, la convivencia y el medio ambiente en las comunidades rurales (Corporación PBA, 2010).

El apoyo de esta Corporación permitió la creación de una asociación con personería 
jurídica denominada Asociación de Innovadores en Productos Ancestrales de Boyacá (Asipaboy). En ella, el trabajo en equipo permite distribuir entre cada uno de los asociados las labores necesarias en todo el ciclo productivo de la arracacha; para ello, tienen un lote en compañía, en el cual siembran empleando métodos como la reproducción in vitro, donde una vez obtenida la cosecha, esta se lleva a transformación y se obtienen diversos productos para comercialización como pan, harina, arequipe y torta (Corporación PBA, 2010).

Así, el conocimiento se transmite a los productores y entre ellos a través de las distintas capacitaciones, talleres y proyectos que se realizan, de tal manera que se integran el conocimiento ancestral heredado y los principios de desarrollo rural sostenible. Ala fecha se han ejecutado con la corporación PBA, el Consorcio Andino y el apoyo de los agricultores, dos proyectos en la materia. El primero de ellos corresponde a un estudio de los diferentes materiales vegetales de arracacha y el segundo hace énfasis en las prácticas de siembra, cortes de colino y desinfección; convirtiéndose en base para la construcción de alternativas que fortalezcan la producción de arracacha.

En este sentido, vale la pena recalcar que los recursos de conocimiento constituyen un factor avanzado, por cuanto los procesos de desarrollo rural sostenible que se están implementando por las corporaciones descritas, permiten atender de forma directa los requerimientos específicos del cultivo, dadas las condiciones particulares en el municipio.

\section{Recursos de capital}

El productor de arracacha acude a dos modalidades para financiar su cultivo. En primer lugar, se encuentra la reinversión con un $60 \%$ de la población encuestada, en la que el agricultor utiliza las ganancias de las cosechas para adquirir los insumos de la nueva siembra, o emplea los rendimientos para actividades como la ganadería.

La segunda modalidad, la de acceso a crédito, al indagar entre los agricultores de arracacha, ellos manifiestan que les ofrecen opciones adecuadas y facilidades tanto en el pago como en los requisitos necesarios, por parte de las entidades bancarias.

El factor recursos de capital representa un obstáculo en la competitividad de la producción, en la medida en que las necesidades de inversión de los productores de arracacha deben ser asumidas por capital propio, pues no se cuenta con incentivos del sector bancario que faciliten el acceso a este.

\section{Condiciones de la demanda}

Corresponde al segundo determinante del diamante de Porter, y permite evidenciar el grado de influencia de la demanda en el sector, y cómo su crecimiento incide en los procesos de innovación y en el nivel de competitividad del mismo. 


\section{Composición de la demanda interior}

El consumidor final se caracteriza por ejercer poca presión sobre los oferentes, para que estos trabajen en procesos de innovación; sin embargo, él tiene amplio conocimiento en lo que respecta a calidad y características propias del producto, dada la experiencia en la compra. La mayoría de los consumidores acude al mercado local o a mercados cercanos como Tunja y Ramiriquí, con los que se tienen extendidas relaciones comerciales.
La proximidad física y cultural entre los demandantes y oferentes locales, contribuye a que la información fluya con mayor facilidad en las redes de comercio, lo cual favorece la comunicación entre los dos actores. Esto tiene como ventaja que las necesidades domésticas puedan ser conocidas de manera rápida, agilizando los niveles de respuesta hacia las mismas.

En cuanto a los volúmenes demandados de arracacha en fresco por departamento, se encuentran los datos contenidos en la Tabla 4 para los años 2011 a 2013.

Tabla 4. Volumen de producción y demanda de arracacha en toneladas, años 2011 y 2012.

\begin{tabular}{|l|c|c|c|c|}
\hline Departamento & 2011 producción & 2011 demanda & 2012 producción & 2012 demanda \\
\hline Tolima & 42.225 & 33.405 & 42.301 & 33.505 \\
Norte de Santander & 10.345 & 31.422 & 13.087 & 31.699 \\
Boyacá & 5.419 & 30.466 & 6.459 & 30.507 \\
Valle del Cauca & 3.066 & 106.288 & 5.226 & 107.384 \\
Cundinamarca & 4.120 & 26.342 & 3.814 & 61.383 \\
\hline
\end{tabular}

Fuente: elaboración de las autoras, con base en análisis sectorial de arracacha y tubérculos andinos en Colombia (Biocomercio, 2013a). Estadísticas agropecuarias de los cinco principales departamentos en producción de arracacha.

Puede observarse que el mercado en el departamento de Boyacá es menor con respecto a otras zonas estudiadas; sin embargo, al examinar detalladamente su volumen de producción de arracacha para el año 2012 fue de 6.459 toneladas, alcanzando una cobertura de la demanda de tan solo el $21 \%$, que es vital atender, como en el caso de Cundinamarca; lo que refleja una demanda insatisfecha en la que el municipio de Boyacá puede intervenir, como una propuesta competitiva.

\section{Sectores conexos y auxiliares}

Dentro de los principales proveedores de insumos para la producción de arracacha, se encuentran los sectores dedicados a la elaboración de fertilizantes y plaguicidas, empaques de fique, abonos y herramientas agrícolas; los cuales en el municipio de Boyacá no tienen gran presencia, por lo que se hace preciso recurrir a mercados cercanos que puedan proporcionar el acceso requerido a dichos mercados. 
Pero, hay que precisar que los insumos empleados para la producción de arracacha, no poseen propiedades especiales para el cultivo, sino que se comercializan de manera generalizada, a su vez, para productos agrícolas como la papa, el maíz, entre otros. No obstante, los agricultores señalan utilizar fertilizantes específicos como Fusilade y Karmex (véase Tabla 1).

En cuanto al empaque empleado para comercializar la arracacha en fresco, se utilizan las lonas en fique, que son adquiridas en el municipio de Boyacá por un valor de 1.000 cada una, y tienen una capacidad de 5 arrobas, es decir 125 libras.

En las tecnologías de producción, por su parte, se evidencia que en el municipio es extendido el uso de herramientas rudimentarias para el manejo de cultivo, tales como azadones, palas, picas y maquinaria como tractor para el arado primario; las cuales son adquiridas en mercados cercanos como Ramiriquí, Tunja y Soracá 5 .

No obstante, vale señalar lo indicado en el estudio Tecnologías de producción local en el municipio de Boyacá, de Gaona (2010, p. 8), en donde se afirma que "a pesar de observarse que la tecnificación del cultivo de arracacha es baja, cálculos basados en los datos de rendimiento, suministrados por los productores, permiten afirmar que el municipio se encuentra entre los de mayor productividad a nivel nacional".

Esta información puede constatarse en los datos consolidados de las estadísticas del Anuario agropecuario 2012, en el que para dicho año el rendimiento (tonelada/ hectárea) de arracacha a nivel nacional era de 11, al igual que para Tolima como principal productor colombiano; mientras que el municipio de Boyacá reportó para dicho tiempo un rendimiento de 15 toneladas por hectárea.

La proximidad entre el sector productor de arracacha y sus sectores conexos, facilita las relaciones comerciales, el flujo de información y el acceso oportuno a insumos. Así, las distribuidoras agrícolas, por ejemplo, brindan al productor un servicio al cliente óptimo traducido en asistencia agrícola, a través de su personal con formación técnica y profesional.

Dentro de la categoría de sectores auxiliares propios del sector, se reconoce principalmente una asociación de productores de arracacha en el municipio de Boyacá, denominada Asipaboy. Dicha asociación se dedica a la elaboración artesanal de productos a base de arracacha, tales como pan, arequipe y tortas, los cuales son distribuidos a consumidores locales y de la ciudad de Tunja, empleando la venta puerta a puerta o por encargo. De igual manera, se tienen como centros de

\footnotetext{
Estos datos fueron suministrados por los agricultores de arracacha, encuestados en el municipio de Boyacá, 2014.
} 
investigación la corporación PBA y la fundación Consorcio Andino, alianza que ha permitido a los agricultores fortalecer su conocimiento en las labores propias del cultivo e incursionar en alternativas como la transformación de arracacha.

Sin embargo, se resalta que la influencia del factor descrito en el diamante de competitividad es baja, pues los sectores conexos son generalizados y sirven de proveedores a otras actividades agrícolas.

\section{Estrategia, estructura y rivalidad}

\section{Estrategia y estructura domésticas}

Al analizar esta categoría dentro del sector productor de arracacha, es preciso en primera instancia señalar que impera la producción familiar en la que se emplea la fuerza de trabajo doméstica y los recursos con que dicha economía cuenta, a fin de garantizar su subsistencia y mejoramiento de la calidad de vida. Los productores de arracacha son empíricos en la administración de sus fincas; en esta medida, es normal encontrar que sea el mismo, como cabeza visible dentro del núcleo familiar, quien se encargue de la toma de decisiones de producción y la distribución del trabajo.

En este sentido, y trayendo a colación los estudios desarrollados por el profesor Orlando Fals Borda (2010), se establece que en el municipio, al igual que en el departamento, prevalece una forma de asentamiento de tipo granja dispersa en la que existe una relación estrecha entre el hogar del agricultor y la tierra que le corresponde, por consiguiente, la casa familiar y las tierras de cultivo comparten el mismo terreno, estando bajo la vigilancia y cuidado del campesino que las habita.

El punto focal en el que es importante prestar atención, considerado como una restricción en la competitividad, es que dentro del modelo social de economía campesina, el agricultor no diferencia sus labores de hogar de sus labores agrícolas propiamente dichas. En este sentido, no se establece el límite entre los recursos empleados para generar un sistema de autoconsumo, y aquellos que corresponden a la producción de arracacha como fuente de ingreso; lo que, en cierta medida, dificulta establecer los rendimientos reales generados por esta actividad comercial.

\section{Metas}

"La prosperidad económica personal, se mide según la cantidad de tierra que el campesino posea" (Fals, 2010, p 141). La rentabilidad percibida por el agricultor es destinada principalmente para el ahorro y posterior compra de nuevos terrenos, en los cuales pueda distribuir de manera eficiente sus cultivos, aprovechando las características de los suelos y las altitudes, a fin de aumentar la productividad y, en consecuencia, los ingresos.

En cuanto a las entidades territoriales, la Alcaldía del municipio de Boyacá tiene como prioridad a diciembre de este año, 
que le sea aprobado un proyecto para la cadena productiva de la arracacha: "Desde la alcaldía y dentro del marco del pacto agrario para la arracacha, se está desarrollando un proyecto que se pasó con los agricultores para la transformación del cultivo, el manejo y la tecnología necesaria para el proceso; se espera la viabilidad de este a diciembre del año en curso; se pasó por \$230.000.000" (M. Pulido, comunicación personal. 21 de septiembre de 2014).

El plan de desarrollo municipio de Boyacá 2012-2015 (Concejo Municipal de Boyacá, 2012, presenta dentro de sus estrategias para el cultivo de arracacha metas como:

- Capacitación a 500 familias en producción limpia.

- Mejorar en un $5 \%$ la especie nativa arracacha.

Los productores de arracacha muestran sus intenciones para la tecnificación del cultivo y se encuentran en la disposición de recibir apoyo de diversas entidades, que les pueda facilitar ese proceso: "Creo que la arracacha es una oportunidad para seguir adelante en el municipio, sobre todo con el apoyo de las investigaciones que realicen las universidades en Boyacá y la tecnificación del cultivo" (P. Mancilla, comunicación personal. 8 de septiembre 2014.)

Dentro de las perspectivas de los agricultores se manifiesta la intención de emplear la producción orgánica: "Se debe apostar un gran esfuerzo, al empleo de la agricultura limpia, pues por ejemplo en la arracacha contribuye a una mayor rentabilidad" (P. Ruiz, comunicación personal. 1 de septiembre de 2014).

Acorde con lo descrito en este apartado, se encuentra una alineación entre las metas de la Alcaldía como ente municipal y la intención de los productores de arracacha, en materia de tecnificación del cultivo y la implementación de agricultura limpia que permitiría aumentar la rentabilidad del cultivo, pues la agricultura limpia propende a la eliminación de fertilizantes y plaguicidas, empleando en cambio la deshierba manual y los abonos caseros. De igual manera, la tecnificación del cultivo, entendida como la adaptación agronómica de suelos, el manejo sostenible y las semillas limpias, contribuirá a entregar al cliente arracacha en fresco de calidad.

\section{Rivalidad doméstica}

La competencia entre los agricultores de arracacha tiene un grado de influencia fuerte, pues al ser una actividad primordial en la economía campesina, constituye una fuente primaria de ingresos para estos. Se reconoce como punto focal de competencia la calidad en el producto: "La competencia es por calidad, desde que uno cultive calidad. Para eso se selecciona bien la semilla, que los colinos no vayan argeniados y se realicen bien las deshierbas" (M. Caro, comunicación personal. 8 de Septiembre de 2014).

No obstante, los productores buscan otras alternativas como la agroindustria para 
apoyar la cadena productiva de la arracacha $\mathrm{y}$ en algunos casos ven que la competencia fuerte "es con otros municipios, no con los productores de Boyacá; ya que se busca fortalecer al municipio y colaborarnos mutuamente, a través de la asociatividad" (E. Quintero, comunicación personal. 8 de septiembre de 2014).

Tabla 5. Producción de arracacha reportada por veredas en el municipio de Boyacá, 2012.

\begin{tabular}{|l|c|c|}
\hline Vereda & Toneladas por año & Participación del total \\
\hline Huerta Grande & 600 & $40 \%$ \\
Soconsaque occidente & 450 & $30 \%$ \\
Pachaquira & 300 & $20 \%$ \\
Rique & 75 & $5 \%$ \\
Rupaguata & 75 & $5 \%$ \\
\hline Total & 1.500 & $100 \%$ \\
\hline
\end{tabular}

Fuente: elaboración de las autoras, con base en consolidado agrícola EVAS Boyacá; Ministerio de Agricultura y Desarrollo Rural. (2013)

En la información recolectada, el factor rivalidad doméstica tiene una fuerte influencia dentro del diamante de competitividad, pues la producción de arracacha constituye una fuente primaria de ingresos para los habitantes del municipio de Boyacá. Por tal motivo, el agricultor busca alternativas como la asociatividad, para acceder a oportunidades que le permitan potenciar el sector y desarrollar ventajas diferenciadoras; para esto, acuden a entidades como el Sena y las universidades, y desarrollan proyectos conjuntos como en el caso de Asypaboy y la corporación PBA.

\section{Papel de la casualidad}

Actualmente, tanto en el municipio de Boyacá como a nivel departamental se presenta un hecho casual que afecta directamente a la población y a las diversas actividades económicas de la misma y se halla fuera del control del Gobierno y los habitantes. Se trata de la escasez de agua, que según expertos, tenderá a extenderse por lo que queda del año, y se podrá evidenciar en estragos como suelos áridos, animales enfermos y presencia de incendios (RCN Radio Boyacá, 2014).

Esta contingencia afecta de manera directa a los agricultores, pues la escasez de agua incide en la productividad de los cultivos y, por ende, aumenta sus costos de producción.

Las medidas que deben tomarse en el momento se encuentran encaminadas hacia el uso racional del agua y la protección de reservas forestales, a fin de garantizar el abastecimiento efectivo a cada uno de los hogares boyacenses, y su preservación, en la ocurrencia de este fenómeno natural. 


\section{Papel del Gobierno}

Los gobiernos territoriales cumplen un rol fundamental, pues sus políticas tienen una amplia influencia en los determinantes descritos que componen el diamante; ya sea de manera positiva o negativa, impactando en la competitividad del sector $\mathrm{y}$, por ende, en su atractivo de inversión, puesto que "las estrategias, surgidas desde y para los territorios, es el eje de las políticas de desarrollo territorial" (Rodríguez, 2014, p. 231).

En esta medida, la Alcaldía de Boyacá se ha propuesto dentro de su plan de gobierno (2012-2015) el fortalecimiento del sector agropecuario, a través de programas que permitan la prestación de servicios de asistencia técnica rural, con los cuales se pretende aumentar la productividad y promover una agricultura orgánica y sostenible.

La Administración municipal propenderá por (sic) la atención regular y continua, a los productores agrícolas, pecuarios y forestales, en la selección del tipo de actividad a desarrollar y en la planificación de las explotaciones, en la aplicación y usos de nuevas tecnologías con agricultura ecológica y sostenible, en la aptitud de los suelos, en la promoción de las formas de organización campesina, en la diversificación de cultivos, para así incrementar los índices de producción, con criterios de competitividad, sostenibilidad y equidad de los principales sistemas productivos del Municipio. (Concejo Municipal de Boyacá, 2012)
Se destaca el desarrollo de tres programas base, de acuerdo con el plan de gobierno de la Alcaldía (2012-2015):

En primera instancia, se tiene el programa servicios agropecuarios que tiene por objetivo aumentar la productividad y el empleo, a partir de la gestión de convenios y proyectos productivos rentables. También está el programa pequeños productores, el cual busca fomentar la asistencia técnica rural, la asociatividad y el uso de una agricultura limpia y sostenible. Para ello, se pretende implementar alternativas de producción limpia, capacitaciones en programas de asociatividad campesina rural, proyectos de mejoramiento del suelo, construcción de una huerta experimental y apoyo a pequeños productores agrícolas.

Por último, se encuentra el programa mejores ingresos, cuyo fin es reducir las tasas de desempleo y el trabajo infantil, a través de la cualificación laboral de jóvenes y el mejoramiento de la capacidad competitiva y productiva empresarial en el municipio.

La alcaldía, como ente territorial del municipio, influencia de manera positiva en el diamante de competitividad, puesto que sus esfuerzos dentro del plan de gobierno se dirigen al fortalecimiento del sector agropecuario, y dentro de este a la arracacha como producto ancestral y primario de su economía.

Dos programas constituyen un apoyo directo a los determinantes analizados en 
el presente estudio; en primera instancia, el programa pequeños productores, que busca emplear la asociatividad como mecanismo para fortalecer el sector arracachero y crear factores diferenciadores frente a la competencia externa, a fin de aprovechar los procesos de innovación que pueden generarse a partir de la intensidad en la rivalidad doméstica. En segunda instancia, el programa mejores ingresos, que fortalece los recursos humanos y recursos de conocimiento, en la medida en que la cualificación laboral permitirá el mejoramiento de la capacidad competitiva y productiva empresarial, retribuyendo lo adquirido en amplio grado al municipio.

FACTORES DE LA COMPETENCIA QUE DETERMINAN LA RENTABILIDAD DE LA INDUSTRIA "CINCO FUERZAS"

\section{Riesgo de ingreso de nuevos compe- tidores}

El riesgo de ingreso de nuevos competidores al sector productor de arracacha del municipio de Boyacá, está dado por la intensidad de las barreras de entrada. Se reconocen como principal barrera, en primera medida, las necesidades de capital, en las que el agricultor encuentra un obstáculo de ingreso de nueva competencia y el tiempo de espera para recibir la rentabilidad, que es de 18 meses.

Así, mientras que para la arracacha se tiene una tasa de rendimiento del 111 $\%$ anual, para la papa, por ejemplo, se presenta una rentabilidad de $96 \%$ semestral, es decir, en el año se obtendría una retribución promedio del $180 \%$ (Ministerio de Agricultura y Desarrollo Rural, 2013). Por ello, el agricultor debería elegir si espera seis meses más para obtener una retribución menor, pero que, a su vez, se encuentra sustentada en una inversión más baja.

En cuanto a la curva de aprendizaje como barrera de entrada, puede destacarse que para los productores de arracacha la participación en distintos proyectos y los conocimientos adquiridos en agricultura limpia, les han permitido perfeccionar sus métodos de producción, especializándolos según las necesidades específicas del municipio de Boyacá.

Por último, se indica que la represalia esperada por los agricultores actuales frente a nuevos competidores tiene influencia nula; pues, no se tienen antecedentes de esta variable y los productores establecidos no cuentan con relaciones sólidas con los canales de distribución o el cliente final.

\section{Intensidad de la rivalidad entre los competidores actuales}

En el municipio de Boyacá hay una fuerte competencia entre los productores de arracacha, marcada por ser una actividad primaria en sus ingresos. Así, la rivalidad intensa proviene de factores como competidores de igual fuerza, pues al estar los agricultores concentrados en una zona geográfica determinada $\mathrm{y}$ 
con recursos similares, la competencia se concentra en la calidad del producto, dada en el color, tamaño y presentación, que se consigue a través de variables como el manejo adecuado de colinos, las deshierbas y los abonos orgánicos.

En cuanto al crecimiento del sector arracachero, no hubo incremento para los años 2011-2012, si se compara con otros municipios como Tibaná $25 \%$ y Saboyá 46\% (Ministerio de Agricultura y Desarrollo Rural, 2013). Por otra parte, la ausencia de diferenciación en el producto y la regulación de precios dada por el volumen de oferta en centrales de abasto y plazas de mercado, hacen más ardua la competencia y exigen en el productor la búsqueda de alternativas que puedan mejorar su posición.

Se encuentra que la principal barrera de salida en el sector, es la barrera cultural, pues la producción de arracacha en el municipio de Boyacá hace parte de un legado tradicional marcado en la vocación agrícola de este cultivo, cuyos conocimientos en sus labores son herencia de generaciones. "Seguiría cultivando arracacha, porque creo que hay que apostarle al campo, ahorita toda la gente joven se está yendo para la ciudad y dejan las fincas. Creo que la arracacha es una oportunidad para seguir adelante en el municipio, sobre todo con el apoyo de las investigaciones que realicen las universidades en Boyacá y la tecnificación del cultivo" (P. Mancilla, comunicación personal. 8 de septiembre 2014)

\section{Presión proveniente de productos sustitutos}

La arracacha es un producto tradicional que goza de buen conocimiento entre la población adulta y mayor en Colombia, siendo más popular en la región andina que en el resto del país, donde se concentra mayormente su consumo. Algunos de los productos que pueden reemplazar el consumo de arracacha como ingrediente dentro de las sopas, son la yuca, la batata, la papa y el ñame. Sin embargo, en la zona central colombiana, el comprador habitual tiene un gran sentido de arraigo hacia ella como ingrediente, y pocas veces la reemplaza o deja de incluirla en su mercado (Biocomercio, 2013a?).

En este sentido, los productos sustitutos del sector no constituyen una fuerte amenaza en la relación precio-desempeño, pues, al igual que este producto, el valor de comercialización de cultivos como la papa o la yuca depende en gran medida de los volúmenes ofertados en los centros de abastos, lo que, a su vez, influye de manera directa en los niveles de rentabilidad que se tengan.

Asimismo, se resalta que la diferenciación de productos sustitutos frente a la arracacha, es nula, pues en ninguno de los casos se reconoce una marca de origen que incida en las preferencias del consumidor final.

\section{Poder de negociación de los clientes}

Dentro del sector productor de arracacha 
se pueden distinguir tres tipos de clientes: los mayoristas, que están altamente concentrados con un amplio poder de negociación y altos volúmenes de compra. Aunado a ello, su relación de dependencia frente a las fluctuaciones en la producción y la baja diferenciación de la misma, les permite incidir en el precio intermedio de arracacha, como primer eslabón de comercialización.

También están los minoristas, con una concentración dispersa, que dependen en alto grado de los canales de distribución mayoristas y manejan volúmenes de compra más bajos que estos. Por tanto, su poder de negociación es limitado, y la retribución que deseen adquirir la transfieren al precio de compra del consumidor final.

Por último, está el consumidor final, quien generalmente compra en volúmenes menores para consumo de su núcleo familiar o dentro de las compras para restaurantes pequeños. Su poder de negociación es bajo. Depende mucho de los canales de distribución y es muy sensible al precio (Biocomercio, 2013 b).

En referencia a los usos industriales potenciales de la arracacha, estos han sido poco explorados, por lo que se encuentra una alternativa eventual para su exploración, sobre todo al considerar su potencial en la industria alimenticia y de farmacéuticos.

Cabe destacar, que a nivel industrial en Boyacá, el consumidor final de arracacha se ve representado por la marca D'labranza; no obstante, al ser un proyecto piloto en etapas de desarrollo, no se cuenta con los datos necesarios para establecer su poder de influencia dentro de la cadena.

\section{Poder de negociación de los proveedores}

La influencia en la negociación de los proveedores del sector arracachero está marcada principalmente por aquellas empresas proveedoras de insumos y fertilizantes agrícolas necesarios para la producción del cultivo, las cuales representan una amenaza en el aumento de precios, pues no están obligadas a competir con productos sustitutos y el sector no constituye un cliente importante.

Asimismo, se encuentra un fuerte poder de negociación por parte de los proveedores de servicio de transporte, quienes inciden en el coste de dicho servicio por valores de gasolina, flete o repuestos.

\section{EI Gobierno como fuerza de competen- cia en la industria}

Para el sector productor de arracacha, el municipio, representante del Gobierno a nivel local, concentra su poder de influencia en los programas agrícolas establecidos, que buscan cualificación laboral, mejoramiento de la capacidad competitiva, asociatividad, productividad empresarial y proyectos para la transformación del cultivo. A partir de los cuales, puede intensificar las barreras para el ingreso de nuevos competidores 
y crear ventajas diferenciadoras, que le permitan reducir el poder de negociación de los clientes y presionar a los productos sustitutos.

\section{CONCLUSIONES Y DISCUSIÓN}

Se destaca que la interacción entre cada uno de los determinantes analizados permite evidenciar la magnitud en que el municipio de Boyacá es un campo fértil para la competitividad del sector productor de arracacha; en donde, la vocación agrícola y el legado ancestral constituyen el arraigo del productor por la actividad, y una barrera de salida sólida de carácter cultural.

La dinámica de las condiciones de los factores se ha visto fuertemente influenciada por la rivalidad domestica presente, lo que ha permitido potencializar la dinámica en factores específicos como los recursos humanos y los recursos de conocimiento, estando en la transición de factores avanzados-generalizados a factores avanzados-especializados, gracias a que los procesos de desarrollo rural sostenible atienden de forma directa los requerimientos específicos del cultivo, dadas sus condiciones particulares en el municipio.

Asimismo, esta concentración de la rivalidad doméstica y la saturación de la demanda local, atrae el apoyo de la Alcaldía en la búsqueda del fortalecimiento de la cadena productiva a través de iniciativas para la tecnificación del cultivo y alternativas de transformación.
Aunque los sectores conexos son generalizados, el contar con personal especialista en insumos agrícolas, proporciona servicios de asistencia técnica apropiados a las necesidades del productor de arracacha. De igual manera, la proximidad geográfica y cultural entre el productor y el sector proveedor, facilita las relaciones comerciales.

Hay que resaltar la alineación entre las metas de la Alcaldía y las intenciones de los productores de arracacha, en materia de tecnificación del cultivo y de implementación de agricultura limpia, sobre todo al reconocer los proyectos piloto de reproducción in vitro y agricultura orgánica que se adelantan, los cuales marcan una diferencia a nivel regional y el desarrollo de agroindustria.

La asociatividad se convierte en el punto clave para lograr procesos de innovación rural sostenibles y fortalecer la competitividad del sector, dentro del marco de la oportunidad de establecer una marca origen.

Las limitaciones presentes en el estudio se enfocan en el carácter estacionario de los resultados encontrados, considerándose la dinámica de los mercados actuales.

En cuanto a las recomendaciones dadas, se precisa la ejecución de un estudio de factibilidad para la creación de un centro de acopio de arracacha en el municipio de Boyacá, fortalecido en amplia medida por la posibilidad de implementar una planta piloto, como centro de estudios de la especie. 
La carencia de un reconocimiento formal de la cadena productiva de la arracacha por parte del Ministerio de Agricultura y de Desarrollo Rural, es una barrera para el establecimiento de políticas claras y acuerdos de competitividad en esta materia; lo que impide al agricultor el acceso a recursos de capital como subsidios y programas que lo apoyen de manera directa. Por tanto, se recomienda la realización de un proyecto que permita crear un acuerdo de competitividad local e indicadores de medición que se ajusten a sus requerimientos.

Considerando que el mayorista es el cliente que posee el más alto poder de negociación y concentración, que incide fuertemente en el precio intermedio de la arracacha en fresco, es de vital importancia implementar acuerdos y alianzas entre los eslabones de cadena, con el fin de apoyar los procesos de desarrollo sostenible para cada uno de los actores.

Como líneas futuras de investigación se visualiza la necesidad de indagar sobre las variables endógenas que conduzcan a proponer modelos propios de medición de la competitividad en sectores que presentan alto grado de informalidad organizacional pero que son vitales en las dinámicas económicas de las regiones no centrales o mayoritariamente rurales.

\section{REFERENCIAS}

Alvarado, E. (2010). Cultivo de arracacha (arracacia xanthorrhiza Bancroft) en los municipios de Turmequé y Boyacá. Tunja, Colombia: Corporación PBA.

Berumen, S. (2006). Una aproximación a los indicadores de la competitividad local y factores de la producción. Revista Cuadernos de Administración Pontificia Universidad Javeriana, 19(31), 145-163.

Biocomercio. (2013a). Análisis sectorial arracacha y tubérculos andinos en Colombia 2012-2013. Recuperado de http://www.biocomerciocolombi a.com

Biocomercio. (2013b). Dimensionamiento y caracterización de la demanda y consumo de tubérculos andinos en Colombia. Recuperado de http://www. biocomerciocolombia.com

Cabrera, A. M., López, P. A. \& Ramírez, C. (2011). La competitividad empresarial: un marco conceptual para su estudio. Documentos de Investigación, (4), 8-54. 
Cardona, M., Castiblanco, S. \& Díaz, H. (2013). Innovación empresarial: una mirada desde la competitividad, el desarrollo local y la transformación productiva para la internacionalización de Colombia. Revista Semestre Económico Universidad de Medellín, 16(34), 149-168.

Carillo, A. \& Cerrutti, M. (2006). Agricultura comercial, empresa y desarrollo regional en el noroeste de México. México D.F.: Universidad Autónoma de Sinaloa.

Cerrutti, M. \& Almaraz, A. (2013). Algodón en el norte de México (1920-1970) impactos regionales de un cultivo estratégico. México: Colegio de la Frontera Norte.

Concejo Municipal de Boyacá. (2012). Plan de desarrollo municipio de Boyacá2012-2015: Unidos Boyacá progresa. Recuperado de http://www. boyaca-boyaca.gov.co

Corporación PBA. (2010). Acerca de la Corporación PBA. Recuperado de http:// corporacionpba.org

DANE (2014). Estadísticas por tema demografía y población- proyecciones de población-. Recuperado de http://www.dane.gov.co/index.php/poblacion-ydemografia/proyecciones-de-poblacion

Fals, O. (2010). EL hombre y la tierra: bases sociológicas e historias para una reforma agraria. Tunja: Ediciones UPTC.

Gaona, A. \& Ochoa, L. (2010). Tecnologías locales de producción de arracacha en el municipio de Boyacá. Revista Actualidad y Divulgación Cientifica Universidad de Ciencias Aplicadas y Ambientales, 13(1), 125-133.

Gereffi, G. (2001). Las cadenas productivas como marco analítico para la globalización. Revista Latinoamericana de Economía: Problemas del Desarrollo, 32(125), 9-37.

Gobernación de Boyacá (2010). Diagnóstico política agrícola en Boyacá. Recuperado en http://www.prooofffpdf.files.wordpress.com

Gonzales, F. \& Guerra, D. (2010). Evaluación de la producción y residuos de cosecha en dos variedades comerciales de arracacha en Boyacá. Tesis de pregrado. Universidad Pedagógica y Tecnológica de Colombia, Tunja, Colombia. 
Haguenauer, J. (1990). La competitividad, una reseña bibliográfica con énfasis en el caso brasileño. Pensamiento Iberoamericano Sociedad Serrarla Quinto Centenario, (17).

Isaza, J. G. (2008). Cadenas productivas: enfoques y precisiones conceptuales. Revista Sotavento MBA Universidad Externado de Colombia, (11), 8-25.

López, C. (2010). Elaboración de estudios de competitividad. Recuperado de http:// www.fpnt.org.mx

Ministerio de Agricultura y Desarrollo Rural. (2013). Consolidado de evaluaciones agropecuarias municipales 2007-2012. Recuperado de http://www.agronet.gov.co

Ministerio de Comercio Industria y Turismo (2013). Boletín noviembre departamento de Boyacá. Recuperado de http://www.mincomercio.gov.co

Muñoz, A., Alvarado, A. \& Almanza, P. (2014). Caracterización preliminar del cultivo de arracacha Arracacia xanthorrhiza Bancoft en el departamento de Boyacá. Revista de Ciencias Agrícolas, Universidad de Nariño, 32(1), 3-11.

Nonsoque, A. \& Suárez, H. J. (1995). Estudio de la oferta de arracacha en el municipio de Boyacá. Tesis de pregrado. Universidad Pedagógica y Tecnológica de Colombia, Tunja, Colombia.

Porter, M. (1991). Ventaja competitiva de las naciones. Buenos Aires: Vergara.

Porter, M. (1999). Estrategia competitiva: técnicas para el análisis de los sectores industriales y de la competencia. México D.F.: Continental.

Rodríguez, E. (2014). Los cuadrantes del desempeño regional en Colombia 2000- 2012. Revista Apuntes del Cenes, 33(57), 223-256.

Sipsa. (2014). Componentes de precios mayoristas. Recuperado de http://www.dane. gov.co

RCN Radio. (2014). El desabastecimiento de agua se siente en Boyacá. RCN Radio. Recuperado de http://www.rcnradio.com 